Article

\title{
Spatio-Temporal Variability of Drought in Pakistan Using Standardized Precipitation Evapotranspiration Index
}

\author{
Shoaib Jamro ${ }^{1, *(\mathbb{D})}$, Ghulam Hussain Dars ${ }^{1}$ (D), Kamran Ansari ${ }^{1}$ and Nir Y. Krakauer ${ }^{2, *(\mathbb{D}}$ \\ 1 U.S.-Pakistan Center for Advanced Studies in Water, Mehran University of Engineering and Technology, \\ Jamshoro, Sindh 76090, Pakistan; ghdars.uspcasw@faculty.muet.edu.pk (G.H.D.); \\ kansari.uspcasw@faculty.muet.edu.pk (K.A.) \\ 2 Department of Civil Engineering and NOAA-CREST, City College of New York, New York, NY 10031, USA \\ * Correspondence: jamroshoaib95@gmail.com (S.J.); mail@nirkrakauer.net (N.Y.K.)
}

Received: 2 October 2019; Accepted: 22 October 2019; Published: 29 October 2019

Featured Application: The following research has a potential to provide a scientific basis for the management of drought mitigation strategies. The trends in drought characteristics in each zone throughout the study period can help decision-makers with more information on resource planning. The identification of contiguous zones with similar drought characteristics across Pakistan is the first step towards developing an integrated and holistic policy to minimize the impacts of droughts. This study will help achieve this goal.

\begin{abstract}
Pakistan is among the top ten countries adversely affected by climate change. More specifically, there is concern that climate change may cause longer and severer spells of droughts. To quantify the change in the characteristics of droughts in Pakistan over the years, we have evaluated spatio-temporal trends of droughts in Pakistan over the period 1902-2015 using Standardized Precipitation Evapotranspiration Index (SPEI). Additionally, the Spatial " $\mathrm{K}$ " luster Analysis using Tree Edge Removal (SKATER) method was employed to regionalize droughts into five contiguous zones. The run theory was then applied to each zone to identify drought events and characterize them in terms of duration, severity, intensity, and peak. Moreover, the Modified Mann-Kendall trend test was applied to identify statistically significant trends in SPEI and drought characteristics in each zone. It was found that the southern areas of Pakistan, encompassing Sindh and most of Baluchistan, have experienced a decrease in SPEI, indicating a drying trend. Central Pakistan has witnessed a wetting trend as demonstrated by an increase in SPEI over time, whereas no statistically significant trend was observed for the northern areas of Pakistan. On a zonal basis, the longest duration drought to occur in Pakistan lasted 22 months in zone 5 (Sindh) from 1968 to 1970. In addition, the droughts of 1920 and 2000 can be said to be the worst drought in the history of the region as it affected all the zones and lasted for more than 10-months in three zones.
\end{abstract}

Keywords: drought regionalization; Pakistan; SPEI; run theory; spatiotemporal analysis

\section{Introduction}

Pakistan is one of the most vulnerable countries to the adverse effects of climate change. Global warming has led to worrisome increases in temperature across the country. The frequency and intensity of extreme events such as droughts, floods, and heatwaves are increasing [1]. Among the extreme events, drought is a frequent occurrence, occuring in about 4 out of 10 years in Pakistan [2]. The nation faced its worst drought—since its creation in 1947—in 1998, which lasted up till 2002 [3,4]. 
This particular drought was due to an El Niño event, which started to develop in the Pacific ocean in 1997 [5].

Several indices have been used to model droughts. Edossa et al. [6] used the self-calibrated Palmer Drought Stress Index (PDSI) [7] to characterize drought events and establish a relationship between hydrological and meteorological droughts in South Africa. Gocic and Trajkovic [8] employed the Standardized Precipitation Index (SPI) [9] in their study to evaluate the spatiotemporal characteristics and patterns of droughts in Serbia. Dabanlı et al. [10] also used SPI at different time scales, along with Principal Component Analysis (PCA), to analyze the spatiotemporal variability of drought in Turkey using 80 years data from 1931 to 2010. Ashraf and Routray [11], Haroon et al. [12], and Xie et al. [13] have used the Standardized Precipitation Index (SPI) to study spatiotemporal drought variability in Baluchistan and Pakistan. However, SPI and PDSI have some major limitations which restrict their use, especially in the context of climate change. PDSI has a fixed time scale and, therefore, multi-timescale aspects of drought cannot be studied by employing PDSI [14]. Precipitation-based indices such as SPI depend on two assumptions: that the variability in precipitation exceeds that of other variables which affect land surface moisture state, and that the other variables, such as temperature, are stationary. However, with global warming expected to increase global temperatures markedly [15], the temperature can no longer be assumed to be stationary. Therefore, to incorporate the effects of a changing climate and allow analyses at different timescales, a novel index, Standardized Precipitation Evapotranspiration Index (SPEI), was introduced by Vicente-Serrano et al. [16], which combines the multi-temporal nature of SPI and its simple calculation procedure with the ability of PDSI to take into account the effect of changes in evaporation demand. Numerous studies focusing on drought monitoring and its spatiotemporal analysis have utilized this index [17-23]. Adnan [17] found SPEI to be one of the most-suited indices to monitor droughts in Pakistan, after comparing 15 indices. Moreover, Potop and Boronean [20] analyzed the evolution of droughts in Czech Republic using SPEI from 1961-2010 for the agricultural season (April-September). They calculated SPEI at different time scales and concluded that SPEI possessed the capability to distinguish the effect of the increase in drought severity due to increasing temperature. Liu et al. [21] regionalized droughts in China based on SPEI for 1961-2015. The use of SPEI allowed the researchers to conclude that increasing temperatures, along with reduced precipitation, were a major cause of droughts in China.

Various studies were carried out to compare SPEI with other indices in the past. In 2015, for example, Tan et al. [22] carried out a spatiotemporal analysis of drought in Ningxia Hui Autonomous Region, China using SPI and SPEI indices. Their study concluded that SPEI is more suitable to explore the link between climate change and drought variation than SPI. More recently, Tian and Quiring [23] used SPEI to analyze spatial and temporal drought patterns in Oklahoma, the United States, from 1901-2014. PCA with VARIMAX rotation was applied to identify four spatially contiguous and homogeneous regions based on 6-month SPEI. The researchers concluded that recent droughts were caused by both a decrease in precipitation and an increase in temperature leading to intensified atmospheric water demands.

The aim of this research is to characterize short-term droughts. Therefore, SPEI at a 3-month timescale will be employed to analyze the spatial and temporal patterns of meteorological drought from 1902-2015 in Pakistan. Additionally, a regionalization technique will be carried out to aggregate grid cells with similar SPEI patterns. Trend analyses will then be applied to the SPEI of different zones and their drought characteristics to identify any statistically significant trends.

\section{Methods}

\subsection{Study Area}

With an area of approximately $796,000 \mathrm{~km}^{2}$, Pakistan (Figure 1) has a diverse climate. Almost two-thirds of its area lies in the arid zone, where slight deviations in climatic parameters often result in devastating consequences [24]. The mean winter temperature in the Upper Indus Basin (northern 
Pakistan) is $2{ }^{\circ} \mathrm{C}-23^{\circ} \mathrm{C}$, while it is $14{ }^{\circ} \mathrm{C}-20^{\circ} \mathrm{C}$ in the Lower Indus Basin (southern Pakistan) $[25,26]$. The mean daily maximum summer temperatures reach $42{ }^{\circ} \mathrm{C}-44^{\circ} \mathrm{C}$ in the Lower Indus Basin, whereas the Upper Indus Basin experiences mean temperatures in the range of $23^{\circ} \mathrm{C}-49^{\circ} \mathrm{C}$ [25].

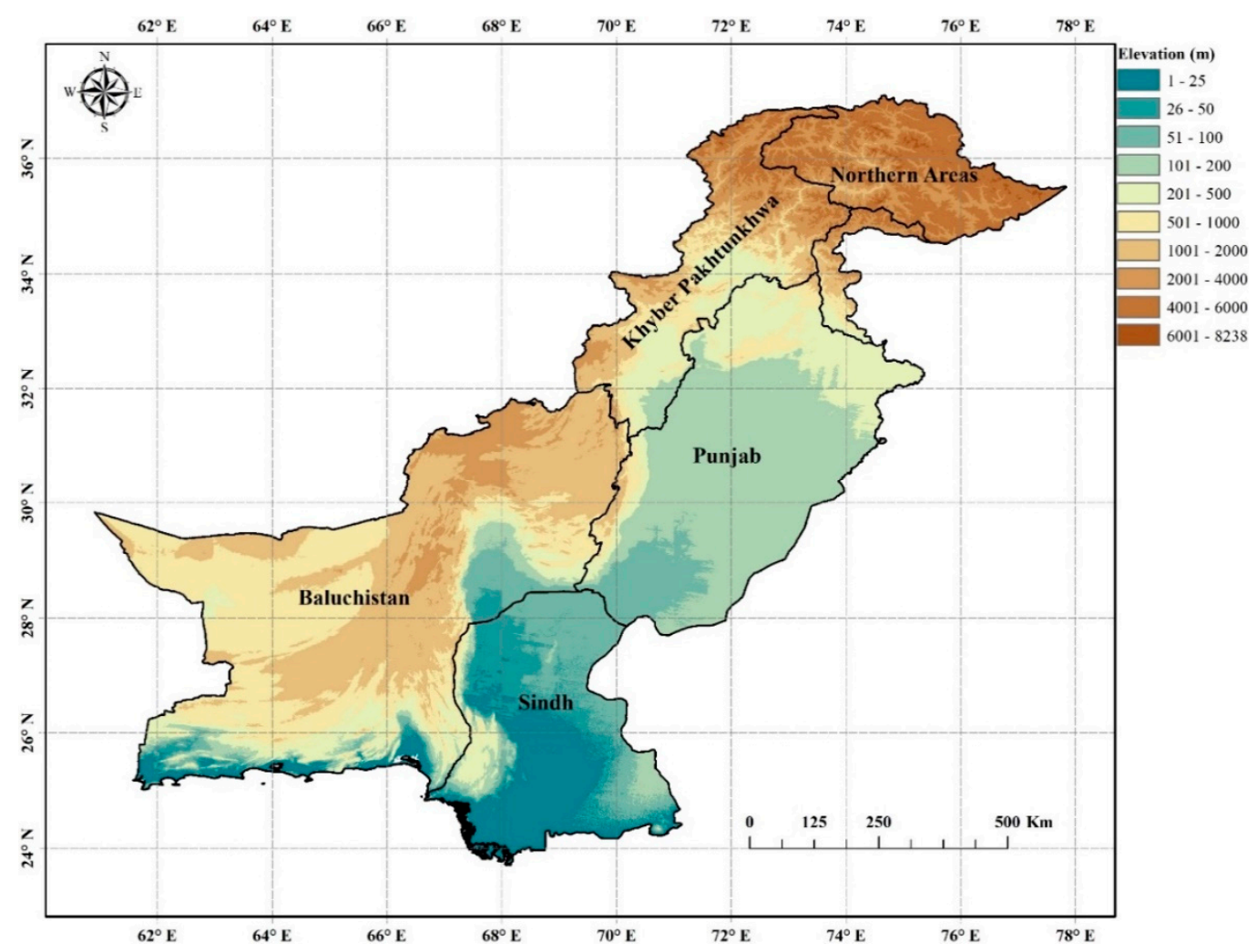

Figure 1. Elevation map of Pakistan.

Total annual precipitation varies from less than $250 \mathrm{~mm}$ in the south to $2000 \mathrm{~mm}$ in the north [25,27]. Two main precipitation systems produce rains in Pakistan. The monsoon, originating from the Bay of Bengal, release rain in the southeastern and eastern regions starting from June and lasting until September [28]. Western weather disturbances, occurring from December to March, bring precipitation to the north and western parts of Pakistan [28]. About 65\% of the country's landmass-Punjab, Khyber Pakhtunkhwa (KPK), eastern Baluchistan, and most of Sindh-falls within the transboundary Indus Basin [29]. The Indus River originates in the Tibetan region of China and traverses Indian Administered Kashmir before crossing into Pakistan and finally draining into the Arabian Sea. The irrigation system developed in the Indus Basin is the world's largest contiguous irrigation system. It is often referred to as the backbone of Pakistan's economy, which relies on it extensively.

\subsection{Methodological Framework}

The methodological framework can be visualized in graphical format (Figure 2). The calculation of 3-month SPEI was carried out for the time period 1902-2015 using precipitation and Potential Evapotranspiration (PET) data from the Climate Research Unit (CRU) dataset. These gridded datasets were then used to acquire 3-month SPEI data from Global SPEI Database, SPEIbase (version 2.5.1), for 1902-2015 at a resolution of 0.5 [30]. The Spatial "K"luster Analysis using Tree Edge Removal (SKATER) method was then applied to all of the 327 grid cells in Pakistan. The country was divided into five zones according to the similarity of SPEI in each cell, keeping into consideration the spatial contiguity of the dataset. For the spatiotemporal analysis, mean drought count, duration and severity were calculated for each grid cell. This was followed by applying the run theory to each of the five zones to characterize the meteorological droughts that occurred from 1902-2015. Droughts were 
characterized in terms of duration, severity, intensity, and peak. Trend analyses were then performed on each of the zones' SPEI and on drought characteristics using the Modified Mann-Kendall test.

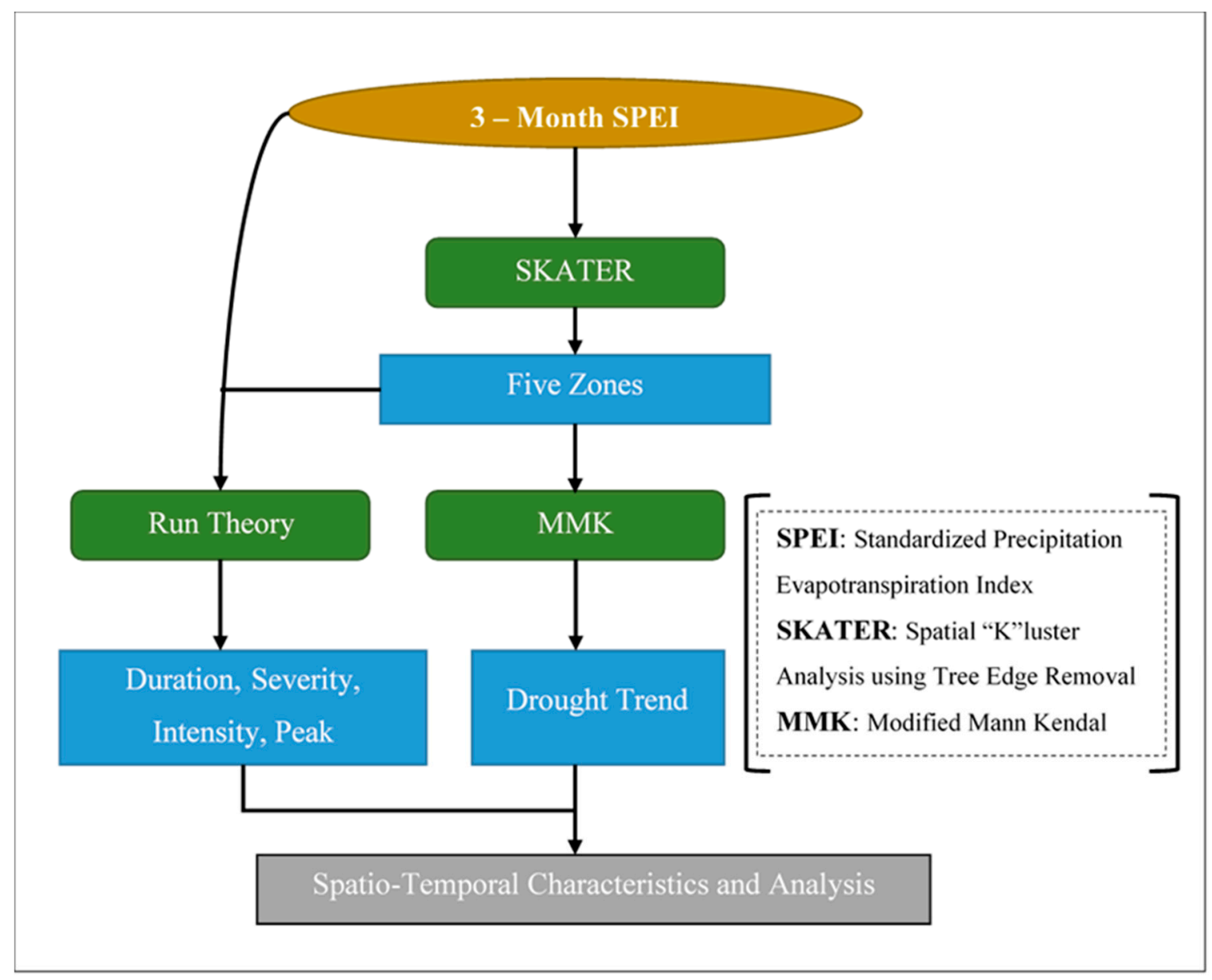

Figure 2. Methodological framework.

\subsection{Meteorological Data}

Gridded potential evapotranspiration and precipitation data provided by CRUat the University of East Anglia (CRU TS 3.24) have been used in this study as the global SPEI database is based on the CRU dataset. The data for monthly time series of 10 climatic variables from 1901 to 2015 are contained in the CRU TS 3.24 dataset at a spatial resolution of $0.5^{\circ}$ by $0.5^{\circ}$, which is roughly $55.5 \mathrm{~km}$ near the equator. The climatic variables included in the dataset are precipitation, potential evapotranspiration, monthly average daily maximum temperature, daily mean temperature, monthly average daily minimum temperature, diurnal temperature range, cloud cover, vapor pressure, frost day frequency, and wet day frequency. The CRU database is created from over 10,000 stations across the globe [31]. The principal sources include World Weather Records decadal data publications, World Meteorological Organization, and monthly climatic data for the world. Due to the number of stations contributing to the dataset varying throughout time, the dataset is not necessarily homogeneous; however, previous studies on trend analysis using CRU dataset have shown promising results [32]. A recent study on the Indus Basin by Krakauer et al. [27] concluded that, despite poor representation of the spatial distribution of precipitation over the Indus Basin using the CRU dataset, the temporal trend of precipitation compared well with that calculated using more stations.

In the CRU dataset, the Correlation Decay Distance (CDD) method [33] is implemented to interpolate the data, such that those stations within the CDD range of a grid cell are used to calculate the value for that grid cell [32]. The gridded values that are produced are thus relatively robust to 
fluctuations in the density of stations. The Penman-Monteith equation is used to calculate PET for each grid cell as this method has been proven better than other simpler methods such as Thornthwaite equation [34], which only makes use of temperature data to estimate PET [35]. Moreover, sensitivity analysis of Penman-Monteith shows that the influence of meteorological parameters on evaporation is almost linear with temperature having the greatest influence on annual evaporation, while the relationship between sunshine duration and evaporation on a monthly scale is not constant. During the winter months, increase in sunshine duration leads to a decrease of evaporation [36]. Both surface energy balance and atmospheric water demand are considered when estimating PET using the Penman-Monteith equation [37].

\subsection{Standardized Precipitation Evapotranspiration Index (SPEI)}

SPEI requires monthly PET data in addition to monthly precipitation data, as it calculates the climatic water balance by subtracting PET from precipitation [16]. Unlike precipitation, the water balance can have values less than zero; therefore, a three-parameter distribution-the log-logistic distribution-is applied to calculate SPEI [16]. As this research focuses solely on meteorological drought, SPEI at a 3-month timescale from 1902-2015 is used to represent drought patterns in Pakistan, with low SPEI corresponding to drought conditions. In total, 327 grid cells cover the entire area of Pakistan. The climatic water balance, $\mathrm{D}$, for the month $\mathrm{i}$ is calculated using the equation below where $\mathrm{P}_{\mathrm{i}}$ represents precipitation and $\mathrm{PET}_{\mathrm{i}}$ represents potential evapotranspiration:

$$
D_{i}=P_{i}-P E T_{i}
$$

The values of $D_{i}$ are then aggregated at varying temporal scales just like SPI. The values of SPEI can be computed for different time scales by fitting a three-parameter probability distribution unlike SPI, which can be calculated using a two-parameter (gamma or Pearson Type III) distribution. This is because three-parameter distribution allows negative values, which is common when computing climatic water balances, whereas in the two-parameter distributions used for precipitation, the lower limit is 0 . The three-parameter distribution that fits well to the $\mathrm{D}$ series at all time scales and in any region in the world is the log-logistic. The resultant probability distribution function of the $\mathrm{D}$ series is given by the following formula [16]:

$$
F(x)=\left[1+\left(\frac{a}{x-y}\right)^{\beta}\right]^{-1} .
$$

The SPEI, then, is the standardized value of $F(x)$ and is obtained by the approximation of Abramowitz and Stegun (1965) given below:

$$
S P E I=W-\frac{C_{0}+C_{1} W+C_{2} W^{2}}{1+d_{1} W+d_{2} W^{2}+d_{3} W^{3}} .
$$

In this equation, $W=\sqrt{-2} \ln (\mathrm{P})$ for $p \leq 0.5$ and $C_{0}, C_{1}, C_{2}, d_{1}$, and $d 2$ are constants. $\mathrm{P}$ here is the probability of exceeding a determined $\mathrm{D}$ value, $p=1-F(x)$. If $p>0.5$, then $p$ is replaced by $1-p$. The sign of the SPEI is then reversed [16].

\subsection{Drought Regionalization}

Regionalizing is a valuable technique used frequently in various disciplines which deal with large spatial datasets. The goal is to preserve the patterns in the dataset and produce homogeneous and contiguous clusters. Spatial "K" luster Analysis using Tree Edge Removal (SKATER) method [38] has been chosen to regionalize droughts in Pakistan because of three reasons. Firstly, SKATER considers the spatial contiguity of the dataset and produces clusters accordingly. This is a crucial consideration when regionalizing drought as it is a spatial phenomenon, so that a comprehensive analysis of this 
hazard requires the preservation of the spatial contiguity of the dataset used to identify droughts. The second reason for choosing this algorithm is the ability of SKATER to include restrictions while clustering. Finally, SKATER has not been employed in regionalizing droughts in Pakistan before.

The SKATER algorithm is an efficient method for regionalization, which "combines the use of a minimum spanning tree with combinational optimization techniques" [38]. SKATER represents the objects as connected graphs, and it captures the adjacency relationship among these objects by creating a connectivity graph, as shown in Figure 3a. A minimum spanning tree can be seen in Figure 3b.

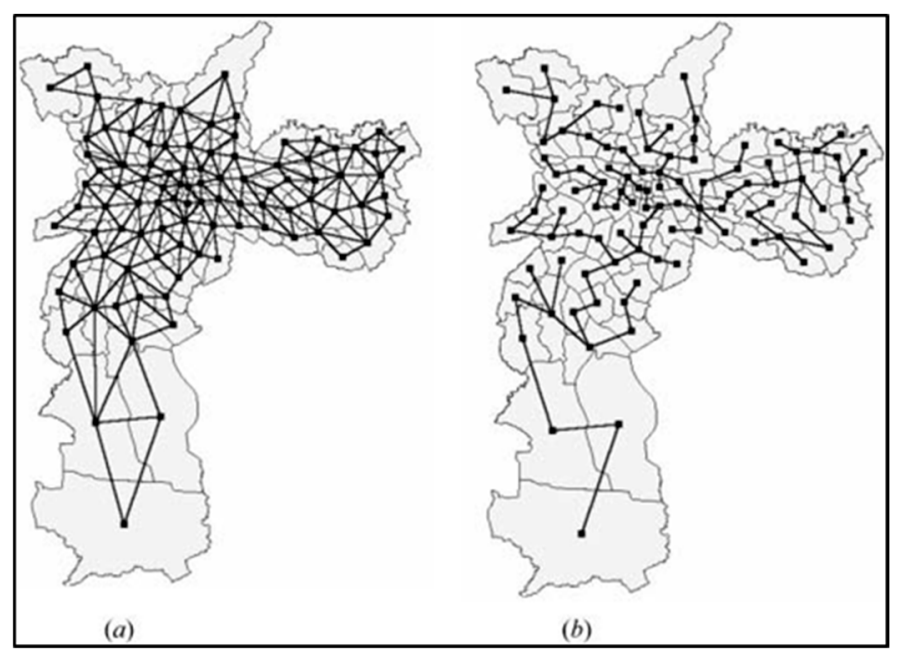

Figure 3. (a) Connectivity graph displaying the adjacency relationship between objects; (b) minimum spanning tree produced after pruning edges with high dissimilarity.

Each object in the figure above is represented as a vertex, which is linked to other vertices by edges. The attribute of interest-the value of SPEI in this case-is signified by the vertex, whereas the relationship to its neighbors is characterized by a "weight," or cost, assigned to the respective edges.

The weight of each edge is directly proportional to the dissimilarity measure between the two vertices it joins. The value of the attribute stored in each vertex is used to calculate the dissimilarity measure, which is then assigned to the edge joining the vertices. Connected clusters are obtained by pruning the graph at suitable places with a high dissimilarity.

A tree is a special type of a connected graph where no circuits are present. A circuit is defined as a path in graphs where "the first and the final nodes (vertices) are the same" [38]. Moreover, a spanning tree of a graph where all the nodes are connected by an exclusive path and the number of edges is one less than the total number of nodes. A Minimum Spanning Tree (MST), in addition, is a spanning tree with the edges having the minimum cost, i.e., the total dissimilarity measure of all the edges combined is the lowest.

Prim's algorithm [39] is used to build the MST recursively. Starting with an empty spanning tree, the algorithm maintains two sets of vertices. The first one contains all the vertices not included in the MST, whereas the other one contains those vertices that are included in the MST. Each iteration picks the edge with minimum cost and moves the endpoint of the edge to the set containing the MST. This process is repeated until all the vertices are included in the set contained in the MST.

A hierarchical division strategy is used to produce clusters in the MST. Initially, a single tree incorporates all the vertices. Each iteration partitions the MST by removing an edge to produce the required number of disconnected trees. The edge to be removed is selected based on the quality of the resulting cluster, which is measured in terms of the sum of the intra-cluster square deviation, which is to be kept to a minimum. Homogeneous regions have a low sum of square deviations. The result is spatially contiguous regions based on a property value assigned to the vertices. 


\subsection{Drought Characterization}

The run theory underlies the identification of drought events. Proposed by Yevjevich [40], the run theory identifies runs based on a threshold level. A run is defined as a portion of time series in which all values are below (or above) a threshold level. A drought event can be decomposed into several components as can be seen in Figure 4. Drought Duration (DD) is defined as the time period-in months-between drought initiation time and drought termination. Drought Severity (DS) specifies the collective deficit of a drought index below the selected threshold level. DS is calculated by simple arithmetic sum of the SPEI deficit for each month under drought. Drought Intensity (DI) is the average of the drought index for a certain drought event. It is calculated by dividing drought severity by its duration. Drought Peak (DP) is the lowest value reached by the index throughout the run's duration. The spatiotemporal drought properties are explored by calculating various drought event indices based on the identified drought events in each region following the methodology of [18]. The arithmetical mean of drought duration, severity, intensity, and peak is used to compare different zones. Several studies have used the run theory for the identification and characterization of droughts $[18,19,21,23,41]$.

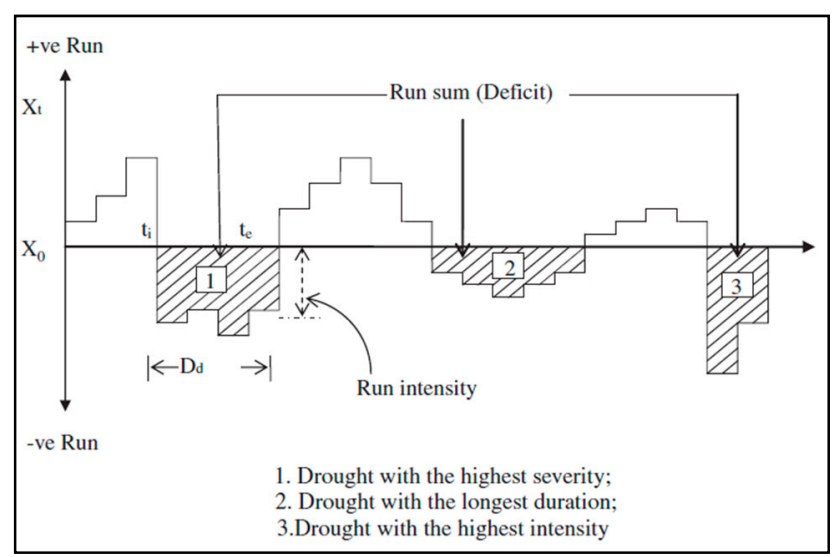

Figure 4. The run theory showing the various drought characteristics it captures.

The possible SPEI values can be divided into the categories shown in Figure 5. This study makes use of the approach employed by Liu et al. [21] where the truncation level is -0.5 , below which drought is said to occur. SPEI values below -1.5 are considered as severe droughts.

\begin{tabular}{|lcc|}
\hline SPEI & Categories & Frequency $(\%)$ \\
\hline $2.0 \leq \mathrm{SPEI}$ & Extreme wetness & 2.2 \\
$1.5 \leq \mathrm{SPEI}<2.0$ & Severe wetness & 4.4 \\
$1.0 \leq \mathrm{SPEI}<1.5$ & Moderate wetness & 9.2 \\
$0.5 \leq \mathrm{SPEI}<1.0$ & Slight wetness & 15.0 \\
$-0.5<\mathrm{SPEI}<0.5$ & Normal & 38.4 \\
$-1.0<\mathrm{SPEI} \leq-0.5$ & Slight dryness & 15.0 \\
$-1.5<\mathrm{SPEI} \leq-1.0$ & Moderate dryness & 9.2 \\
$-2.0<\mathrm{SPEI} \leq-1.5$ & Severe dryness & 4.4 \\
$\mathrm{SPEI} \leq-2.0$ & Extreme dryness & 2.2 \\
\hline
\end{tabular}

Figure 5. SPEI classification.

\subsection{Trend Analysis}

The Modified Mann-Kendall (MMK) trend test, as proposed by Hamed and Rao [42], was used to detect any statistically significant trends in SPEI and drought characteristics of each zone. MMK is an 
improvement over the original non-parametric Mann-Kendall trend test [43]. MMK is robust when autocorrelation is present in the data and is based upon the modified variance of S-the Mann-Kendall Test Statistic. To calculate MMK, a non-parametric trend estimate [44] is subtracted from the time series. The detrended series is then used to calculate the autocorrelation between the ranks of the observations. Finally, a modified variance of $S$ is evaluated using autocorrelations which are statistically significant at the $5 \%$ level.

\section{Results}

\subsection{Drought Regionalization}

Five homogeneous and contiguous zones were developed after applying the SKATER algorithm (Figure 6). The zones produced are similar to the climatic zones developed by [45]. Region 1 (North) covers the northern part of Pakistan, which is heavily glaciated and receives considerable snowfall. The second region (Central) includes northern Baluchistan and some parts of southern Punjab and southern Khyber Pakhtunkhwa (KPK). The rest of Punjab and KPK form region 3 (East), whereas central and southern Baluchistan form region 4 (Southwest). Region 5 (Southeast) contains the province of Sindh.

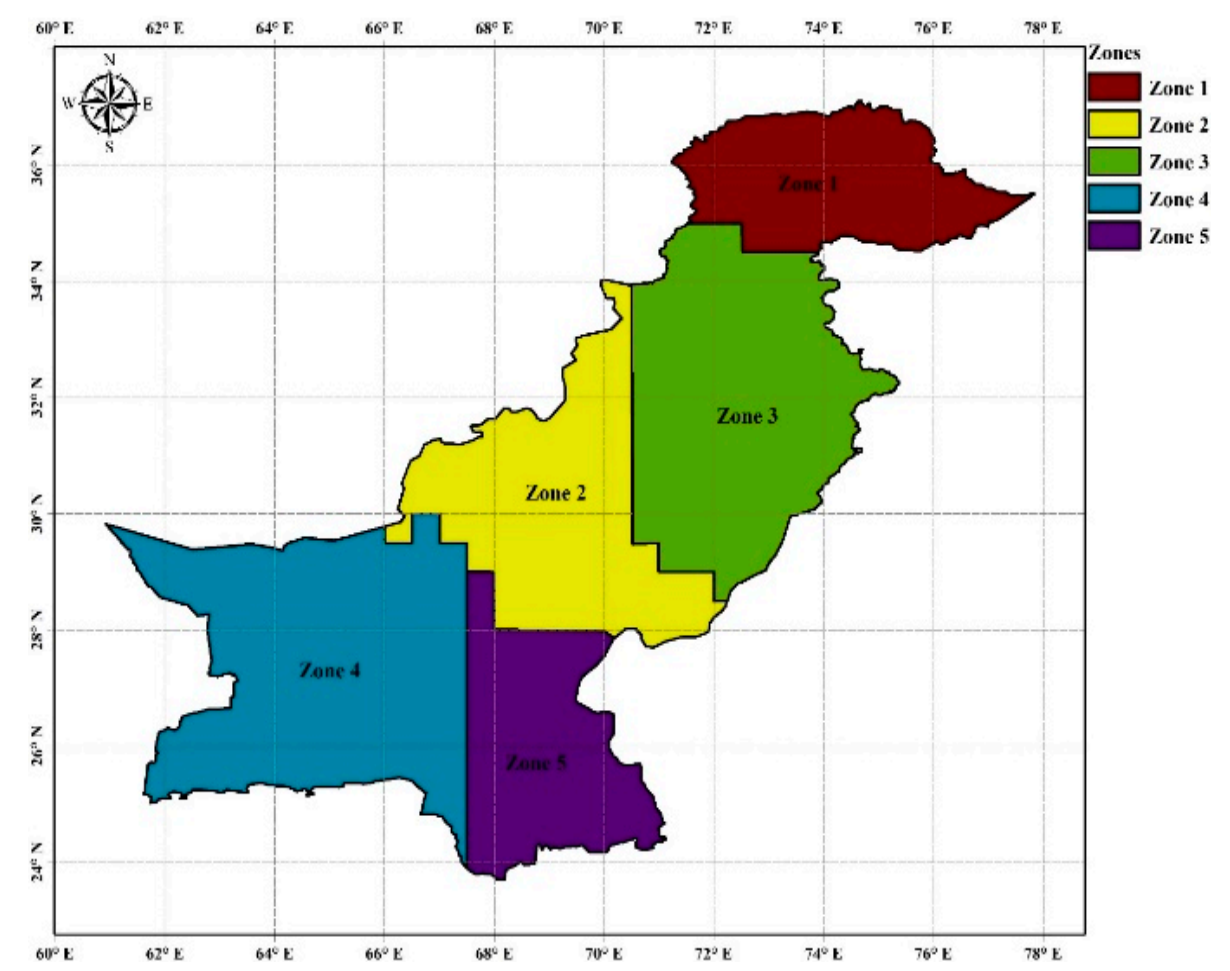

Figure 6. Zones produced after regionalization.

\subsection{Spatial Analysis}

The runs theory was applied to each region to identify drought events and characterize them in terms of duration, severity, intensity, and peak. Figures 7-9 display the drought count in each grid cell along with the mean duration and severity. 


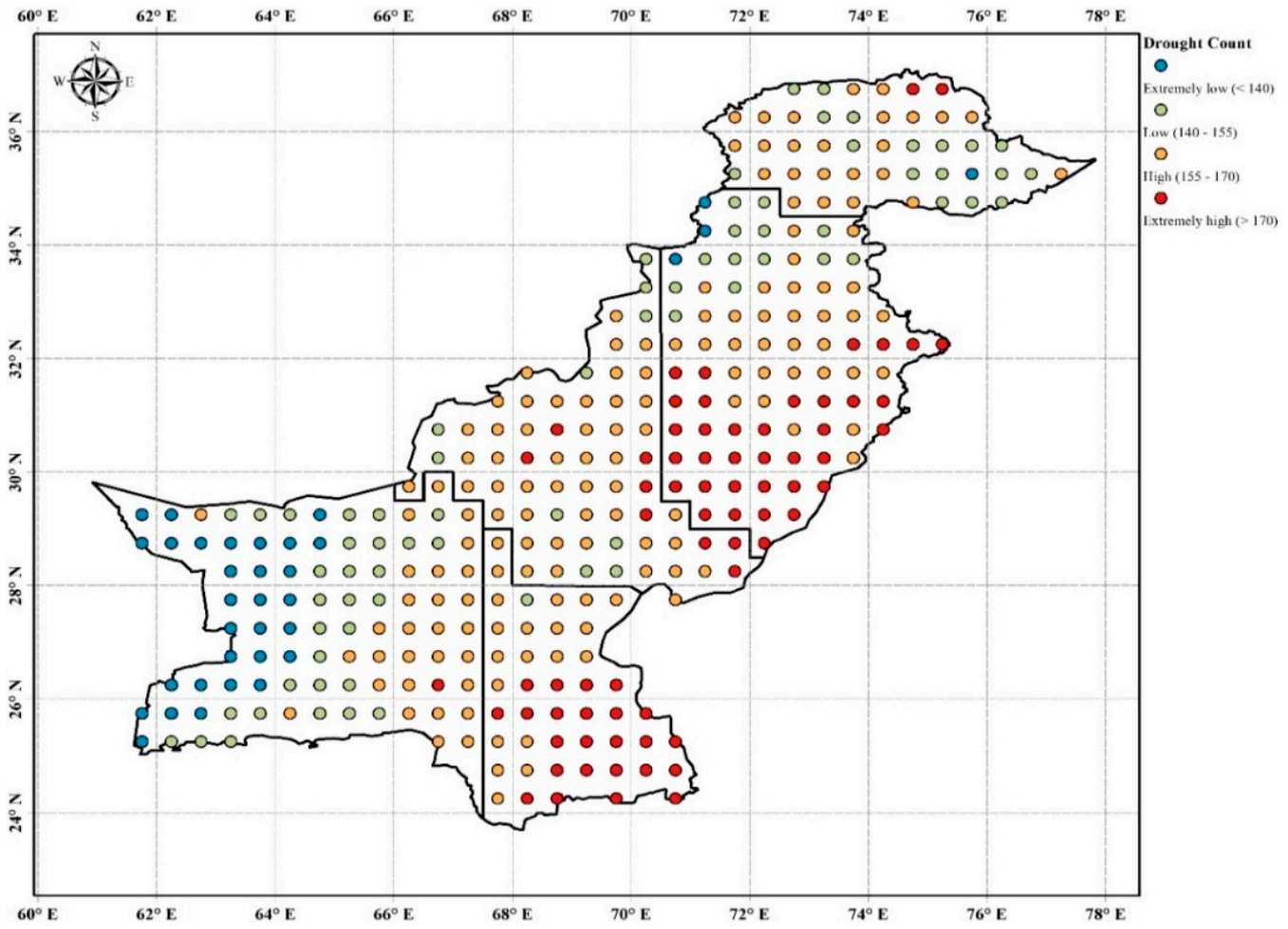

Figure 7. Drought count at each grid cell.

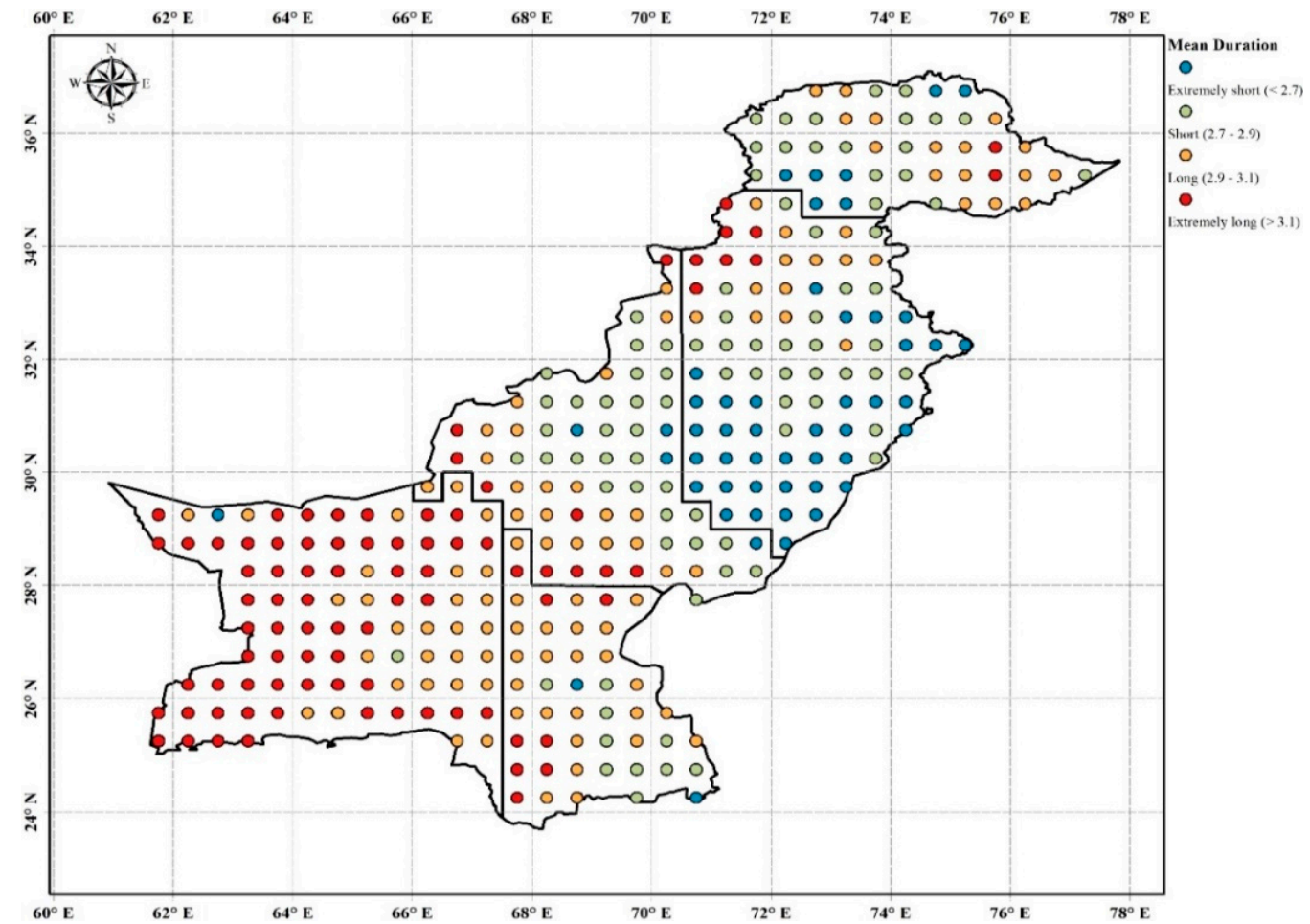

Figure 8. Mean duration of droughts that occurred from 1902-2015 at each grid cell. 


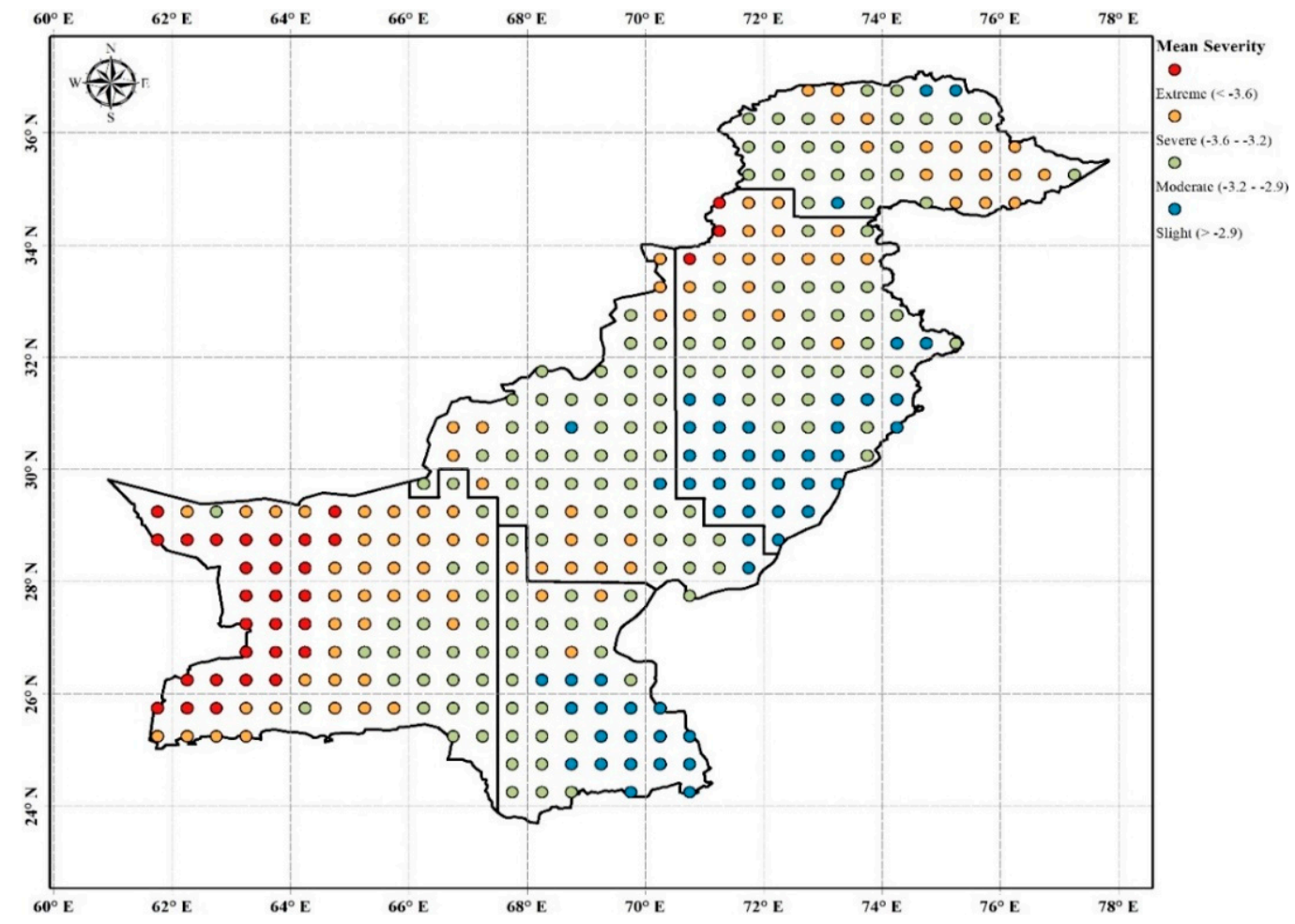

Figure 9. Mean severity of droughts that occurred from 1902-2015 at each grid cell.

From Figure 7, it is clear that there are remarkable variations in drought count across Pakistan. Zone 1 mostly experiences a low to high number of droughts with a few grid cells-bordering China - experiencing an extremely high number of droughts. Moving southwards into zone 3 , the number of droughts decrease at first before increasing to high and then extremely high.

High drought count mostly dominates zone 2, except for its southern part where an extremely high number of droughts occur. In zone 4, we again see a pattern of decreasing drought count moving westwards. The northern and western borders of zone 5 experience a high number of droughts, in contrast to the rest of that region that encounters an extremely high number of droughts.

Moreover, an interesting pattern in contrast to Figure 7 can be observed in Figure 8, which displays the mean duration for grid cell from 1902-2015. The areas with high drought count have extremely short (in Zone 3) and short (in zone 5) duration of droughts. On the other hand, the zones experiencing an extremely low number of droughts (zone 4) have the longest duration. This observation makes sense as SPEI is a normalized index with approximately equal probability of SPEI being less than -0.5 for each grid cell. The number of drought months is therefore approximately equal for all grid cells. Since the number of drought months is equal to the product of mean duration and drought count, drought duration and drought count have a strong negative correlation. From Figure 9, it can be concluded that regions that experience a low number of meteorological droughts are usually struck with longer and more severe droughts and vice versa. However, the most severe droughts are concentrated in west Baluchistan.

Drought management and mitigation in Region 1 should focus on moderate and severe drought, whereas, in Region 2, the focus should be on highly frequent droughts with moderate severity and duration. The south of Region 3 experiences an extremely high number of droughts with extremely short duration and slight severity. The north of Region 3, on the other hand, is struck with a low number of droughts but increasing severity and duration. Region 4 also shows spatial variability with the western part experiencing an extremely low number of droughts of extremely high duration and extreme severity. The southeast of Region 5 is distinct from the rest of the region with an extremely 
high number of droughts of extremely low duration and slight severity as compared to the rest of Region 5, which faces a high number of droughts of long duration and moderate severity.

\subsection{Temporal Analysis and Trend Analysis}

The temporal analysis of droughts sheds light on the long-term drought conditions of that region and, therefore, are a significant part of drought study. Figures 10-14 display the 3-month SPEI of each region from 1902-2015 along with the least squares regression line. The wet and dry periods can be clearly visualized. Substantial differences in the drought characteristics in each zone were observed. Figures 15-18 show the drought duration, severity, intensity, and peak for each zone from 1902-2015.

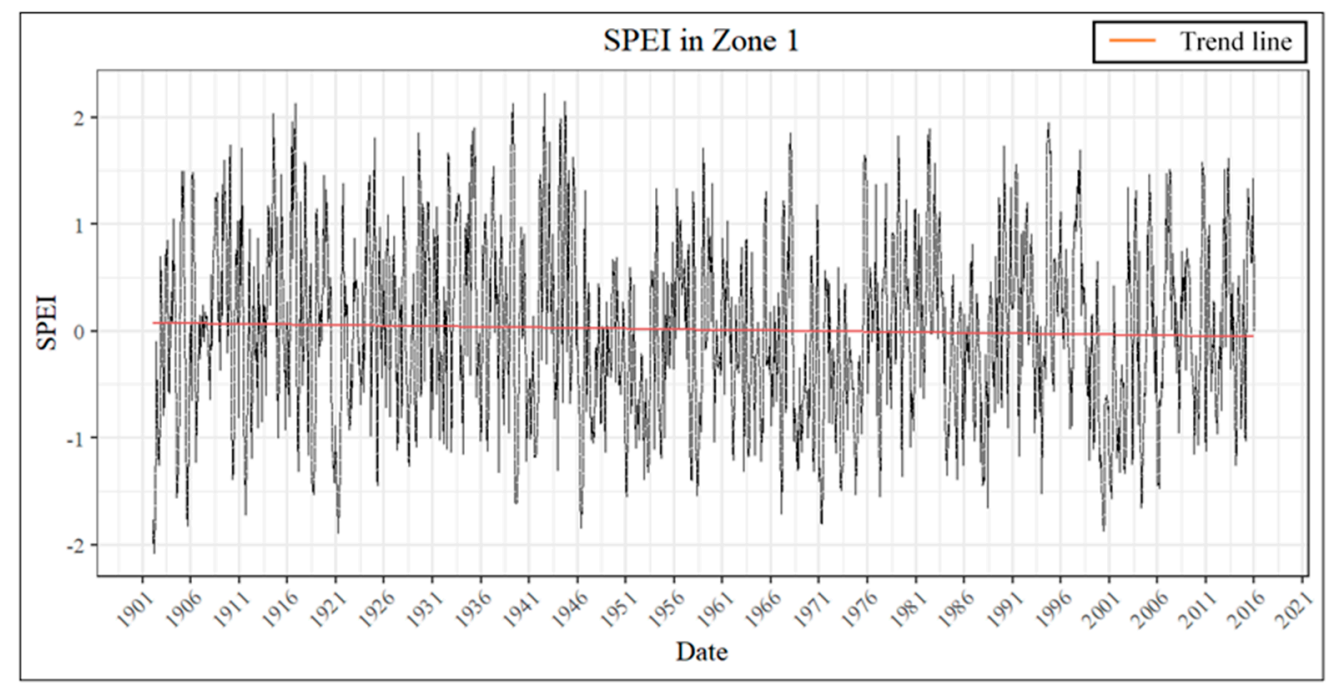

Figure 10. Three-month SPEI from 1902-2015 for zone 1.

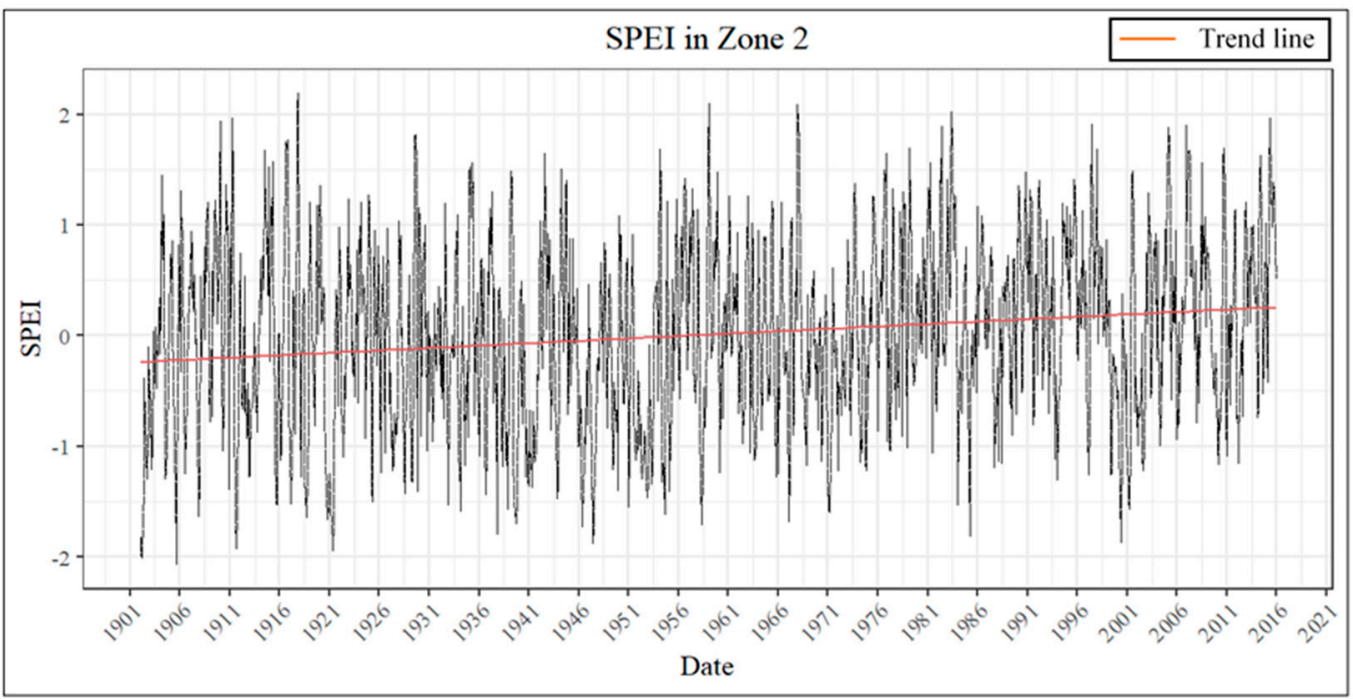

Figure 11. Three-month SPEI from 1902-2015 for zone 2. 


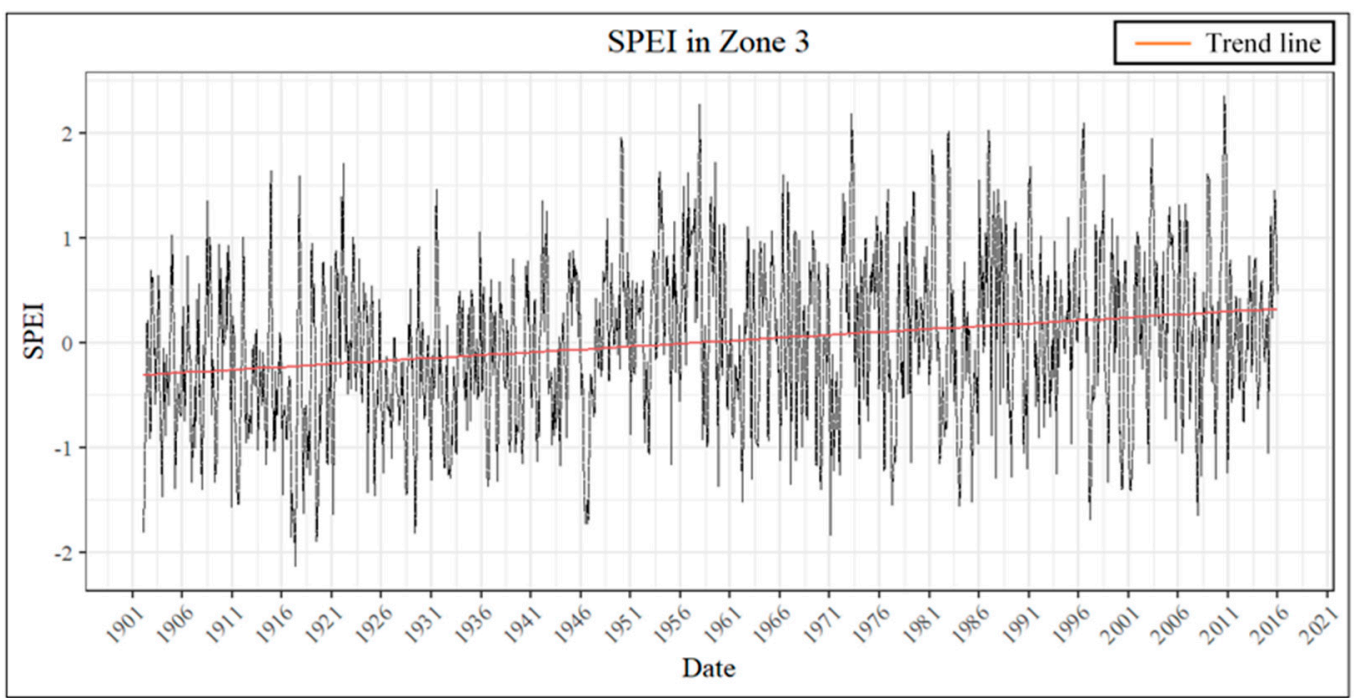

Figure 12. Three-month SPEI from 1902-2015 for zone 3.

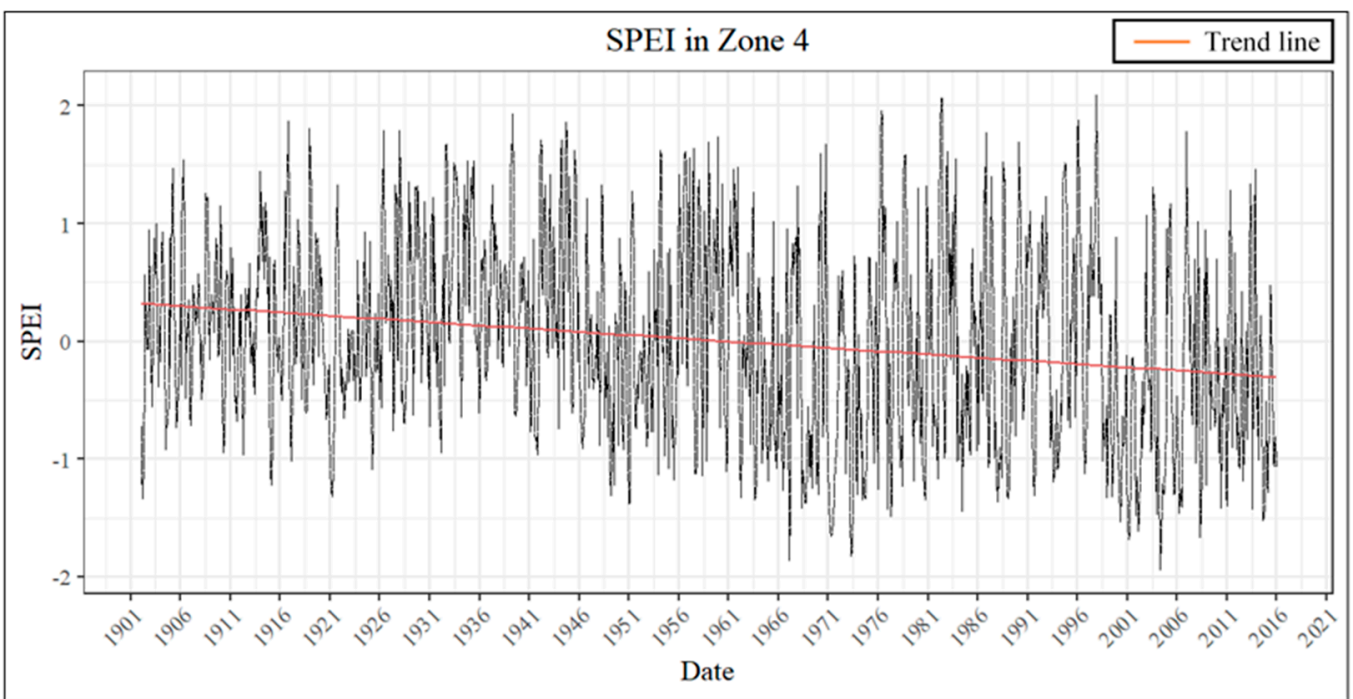

Figure 13. Three-month SPEI from 1902-2015 for zone 4.

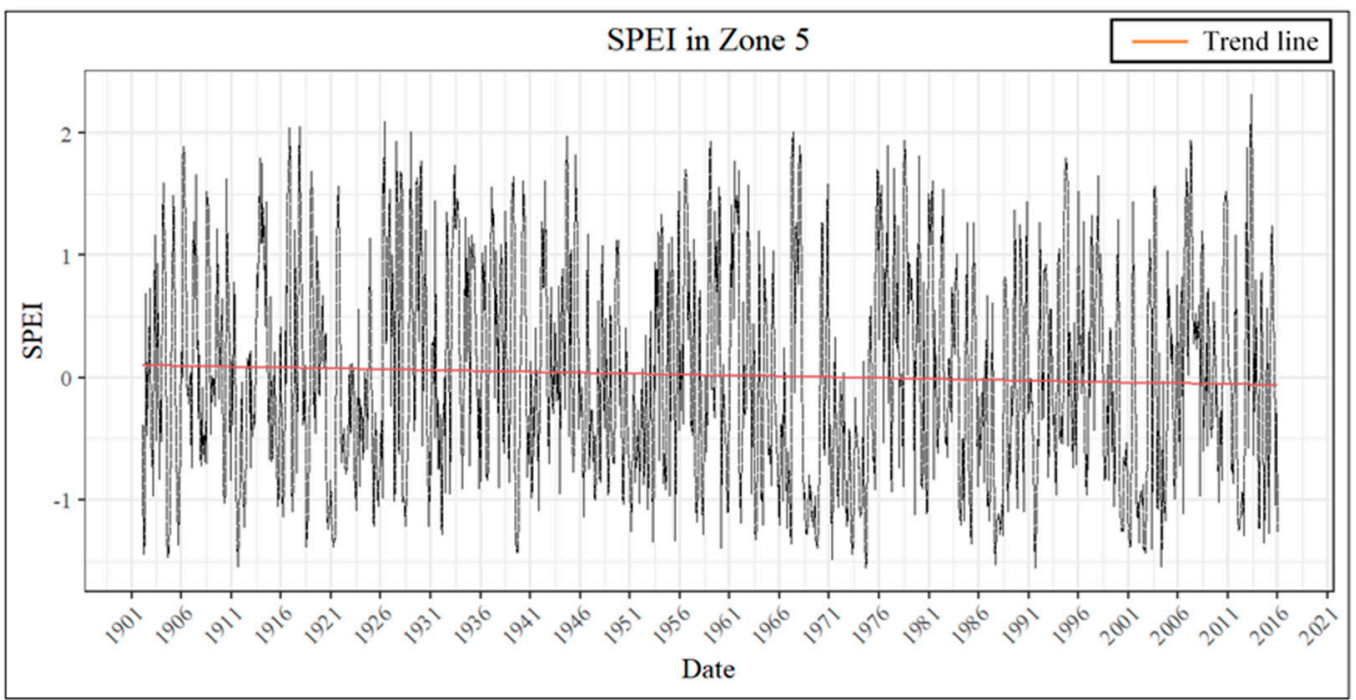

Figure 14. Three-month SPEI from 1902-2015 for zone 5. 


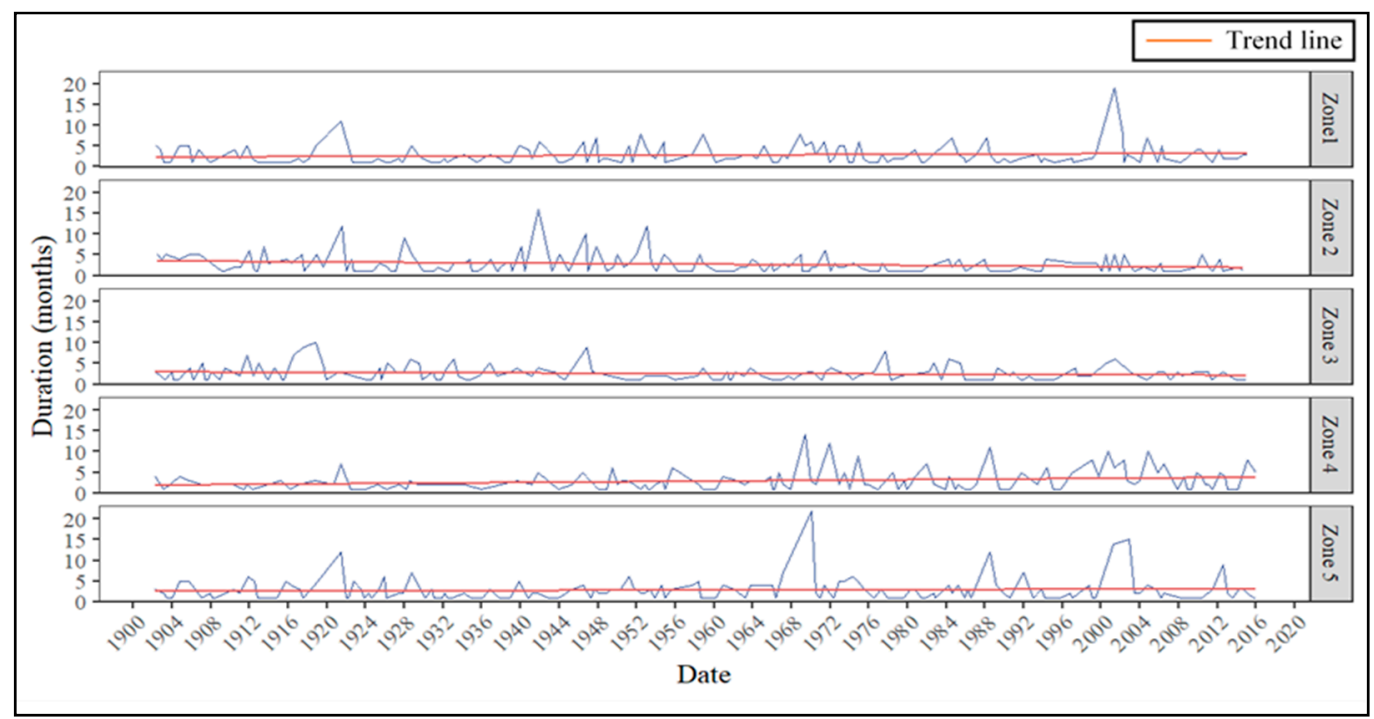

Figure 15. Drought durations for each zone.

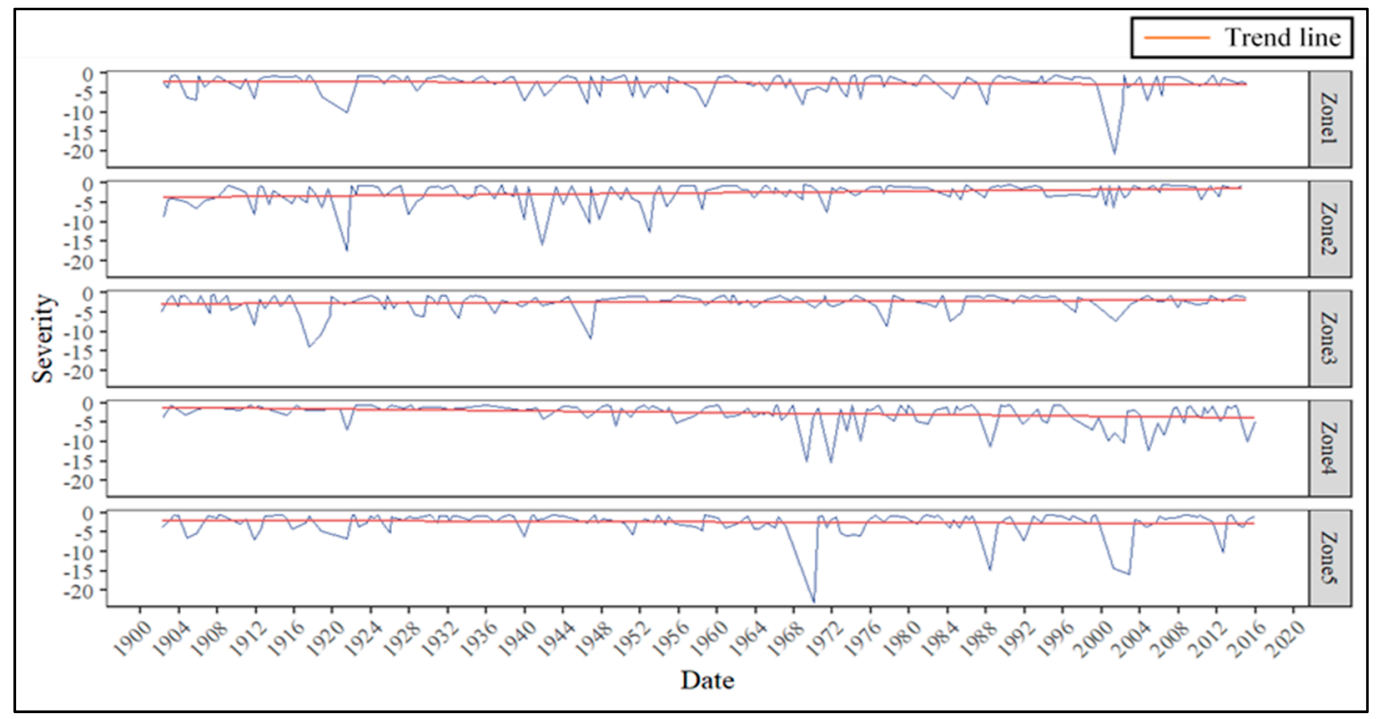

Figure 16. Drought severities for each zone. 


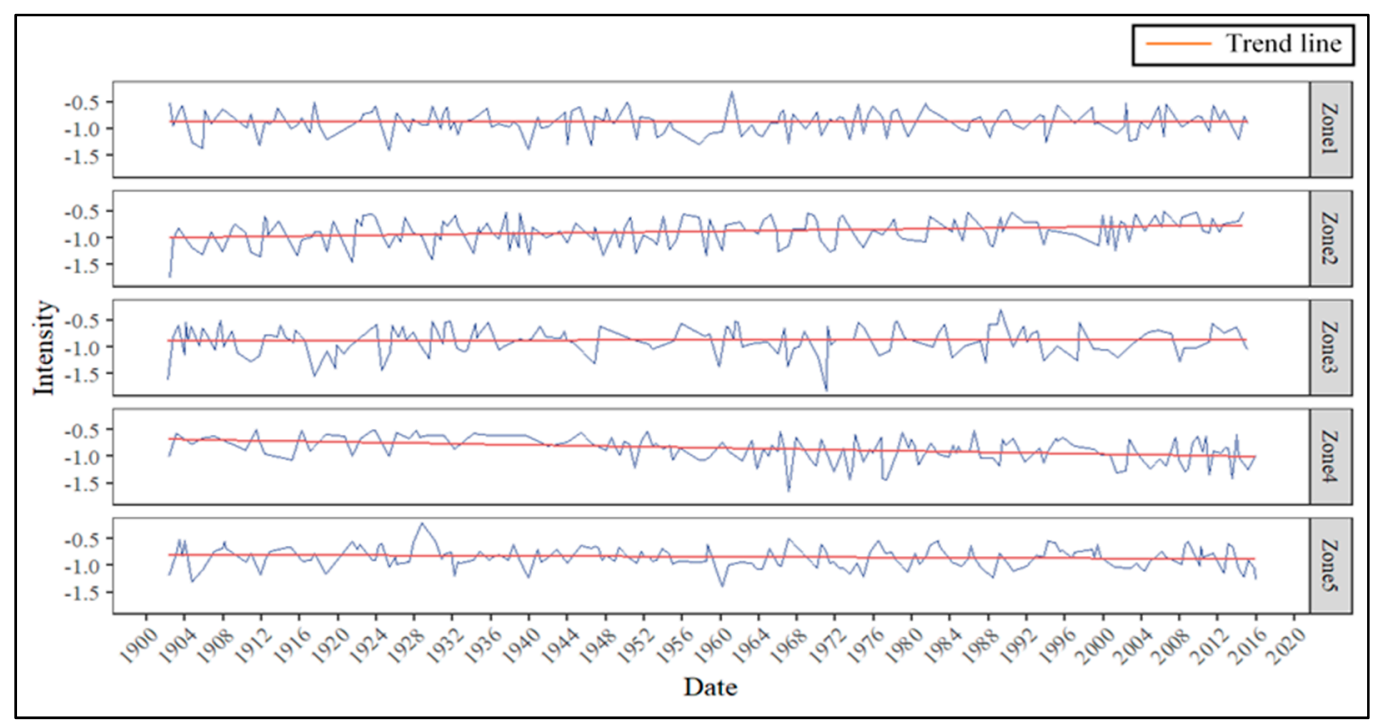

Figure 17. Drought intensities for each zone.

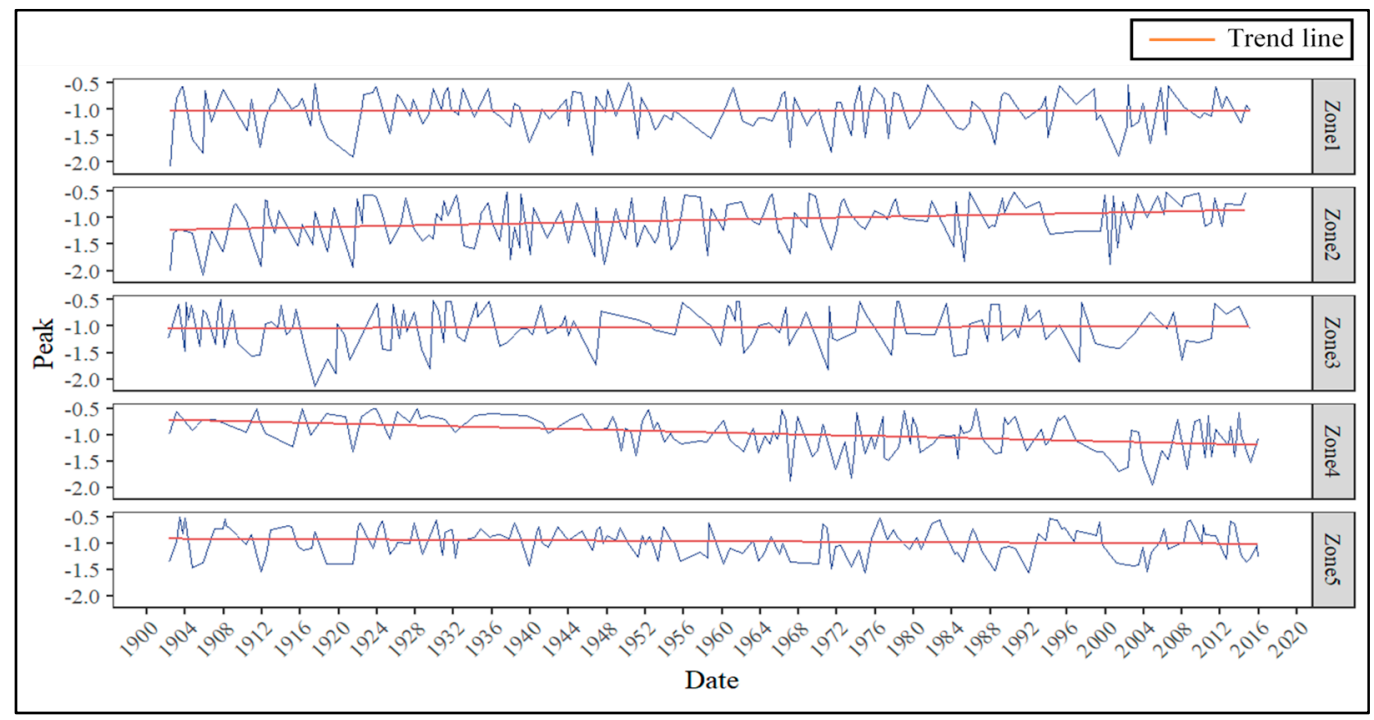

Figure 18. Drought peaks for each zone.

In zone 1, three events are of particular interest. The first is the period from 1946-1953, where, in addition to experiencing multiple droughts, the SPEI in the area never exceeded the 0.75 mark. Three severe droughts also occurred in this period. A similar dry pattern is seen from 1984-1989 in which the positive SPEI remained considerably less than 1. Finally, the four-year period from 1998-2002 also displays an extended period of dryness.

For zone 2, the drought behavior can be divided into two distinct periods. Droughts before 1960 occurred for longer duration and were comparatively more severe than droughts occurring after 1960, as can be seen from Figures 15 and 16 .

Observing the drought characteristics in zone 3, an extreme drought can be seen in the late 1910s. The minimum SPEI dropped below -2 and, therefore, can be said to be the worst drought in this zone's history in terms of duration, severity, and peak. Other long-term droughts occurred in 1946 and 1977 which lasted nine and eight months, respectively, as is seen in Figure 15.

Drought behavior in zone 4 can be explained in two distinct periods, just like in zone 2. From Figure 15, we can identify the period before 1967, which experienced comparatively short-term droughts as compared to the long-term droughts that occurred after 1967. 
Throughout the study period, drought peak in zone 5 never fell below -1.6 as can be seen in Figure 18. However, looking at Figure 15, we can see that droughts with longer duration and greater severity have occurred in zone 5 as compared to other zones. After a long-term drought in the early 1920s, the area experienced dry spells again at the end of 1967, 1987, and 1999.

Table 1 summarizes the results of the Mann-Kendall trend test applied to SPEI, drought duration, severity, intensity, and peak of each zone. The SPEI in each zone except zone 1 demonstrates a statistically significant trend after applying the modified Mann-Kendall trend test. Zones 2 and 3 are getting wetter over time, whereas zones 4 and 5 display a drying trend as signified by their respective Sen's slope value. The trend analysis did not capture any trend in drought duration in any zone. Drought severity in zones 1 and 4 is getting worse, but it is lessening in zone 2. Zones 3 and 5 show no statistically significant trend for drought severity.

Table 1. Modified Mann-Kendall trend test results.

\begin{tabular}{|c|c|c|c|c|}
\hline \multicolumn{5}{|c|}{ Modified Mann-Kendall Trend Test } \\
\hline & & $P$-Value & Tau & Sen's Slope \\
\hline \multirow{5}{*}{ Zone 1} & SPEI & $5.05 \times 10^{-2}$ & $-2.84 \times 10^{-3}$ & $-9.91 \times 10^{-5}$ \\
\hline & Duration & $1.52 \times 10^{-2}$ & $9.09 \times 10^{-2}$ & $0.00 \times 10^{0}$ \\
\hline & Severity & $5.86 \times 10^{-4}$ & $-7.63 \times 10^{-2}$ & $-2.47 \times 10^{-3}$ \\
\hline & Intensity & $9.41 \times 10^{-1}$ & $-1.27 \times 10^{-3}$ & $-1.23 \times 10^{-5}$ \\
\hline & Peak & $1.92 \times 10^{-1}$ & $-2.15 \times 10^{-2}$ & $-2.73 \times 10^{-4}$ \\
\hline \multirow{5}{*}{ Zone 2} & SPEI & $2.08 \times 10^{-12}$ & $1.12 \times 10^{-1}$ & $3.87 \times 10^{-4}$ \\
\hline & Duration & $4.72 \times 10^{-2}$ & $-1.16 \times 10^{-1}$ & $0.00 \times 10^{0}$ \\
\hline & Severity & $1.24 \times 10^{-3}$ & $1.57 \times 10^{-1}$ & $5.15 \times 10^{-3}$ \\
\hline & Intensity & $8.18 \times 10^{-23}$ & $1.63 \times 10^{-1}$ & $1.30 \times 10^{-3}$ \\
\hline & Peak & $1.15 \times 10^{-30}$ & $1.81 \times 10^{-1}$ & $2.23 \times 10^{-3}$ \\
\hline \multirow{5}{*}{ Zone 3} & SPEI & $1.15 \times 10^{-18}$ & $1.54 \times 10^{-1}$ & $4.72 \times 10^{-4}$ \\
\hline & Duration & $1.86 \times 10^{-1}$ & $-5.77 \times 10^{-2}$ & $0.00 \times 10^{0}$ \\
\hline & Severity & $1.70 \times 10^{-1}$ & $5.04 \times 10^{-2}$ & $1.90 \times 10^{-3}$ \\
\hline & Intensity & $5.71 \times 10^{-1}$ & $-1.09 \times 10^{-2}$ & $-8.95 \times 10^{-5}$ \\
\hline & Peak & $9.24 \times 10^{-1}$ & $2.10 \times 10^{-3}$ & $2.49 \times 10^{-5}$ \\
\hline \multirow{5}{*}{ Zone 4} & SPEI & $7.32 \times 10^{-18}$ & $-1.49 \times 10^{-1}$ & $-4.96 \times 10^{-4}$ \\
\hline & Duration & $1.44 \times 10^{-1}$ & $9.55 \times 10^{-2}$ & $0.00 \times 10^{0}$ \\
\hline & Severity & $1.34 \times 10^{-3}$ & $-1.64 \times 10^{-1}$ & $-7.73 \times 10^{-3}$ \\
\hline & Intensity & $8.20 \times 10^{-14}$ & $-2.63 \times 10^{-1}$ & $-2.26 \times 10^{-3}$ \\
\hline & Peak & $9.08 \times 10^{-16}$ & $-2.68 \times 10^{-1}$ & $-3.26 \times 10^{-3}$ \\
\hline \multirow{7}{*}{ Zone 5} & SPEI & $8.72 \times 10^{-5}$ & $-3.83 \times 10^{-2}$ & $-1.34 \times 10^{-4}$ \\
\hline & Duration & $8.84 \times 10^{-1}$ & $4.04 \times 10^{-3}$ & $0.00 \times 10^{0}$ \\
\hline & Severity & $3.91 \times 10^{-1}$ & $-2.25 \times 10^{-2}$ & $-5.12 \times 10^{0}$ \\
\hline & Intensity & $2.11 \times 10^{-1}$ & $-3.32 \times 10^{-2}$ & $-2.25 \times 10^{-4}$ \\
\hline & Peak & $9.63 \times 10^{-4}$ & $-7.86 \times 10^{-2}$ & $-7.26 \times 10^{-4}$ \\
\hline & & \multirow{2}{*}{\multicolumn{3}{|c|}{$\begin{array}{l}\text { Statistically significant at } 95 \% \text { confidence internal } \\
\text { Not statistically significant }\end{array}$}} \\
\hline & & & & \\
\hline
\end{tabular}

Moreover, the positive value of Sen's slope for drought intensity in zone 2 indicates an increasing value of intensity over time, which means drought is getting less intense. In contrast, zone 4 has a negative Sen's slope, which means that droughts are getting less intense with time. No statistically significant trend was observed in zones 1,3, and 5. Furthermore, drought peaks show an increasing trend in zone 2 and, therefore, peaks are getting smaller (less negative) over time. Peaks in zones 4 and 5 show a negative trend indicating that peaks are getting worse over time, whereas no significant trend was detected for zones 1,2 , and 3 .

Characteristics of droughts in each zone of duration more than 10 months are tabulated in Table 2. Zone 1 had two instances of droughts having a duration of more than 10 months. The first started in late 1999 and ended in mid-2001. It lasted 19 months with a mean intensity of -1.10 . The other 
long-duration drought occurred for a total 11 months from August 1920 and lasted till June 1921. Zone 2 suffered four long-term droughts. One occurred in the early 1920s, two in the 1940s, and one in the early 1950s. Zone 3 had a long-term meteorological drought in the late 1910s. Zones 4 and 5 were struck with the greatest number of droughts (5) having a duration greater than 10 months. Zone 4 witnessed droughts in the late 1960s, early 1970s, late 1980s, late 1990s, and mid-2000s. The most intense drought, with an intensity of -1.29 , was the one in the early 1970s, whereas the drought in the mid-2000s experienced the worst peak with a magnitude of -1.94 .

Table 2. Drought characteristics of droughts with duration $\geq 10$ months.

\begin{tabular}{ccccccc}
\hline Zone & Start & End & Duration (Months) & Severity & Intensity & Peak \\
\hline \multirow{2}{*}{ Zone 1 } & 16 November 1999 & 16 May 2001 & 19 & -20.92 & -1.10 & -1.88 \\
& 16 August 1920 & 16 May 1921 & 11 & -14.98 & -1.36 & -1.89 \\
& 16 July 1940 & 16 October 1941 & 16 & -15.91 & -0.99 & -1.38 \\
Zone 2 & 16 July 1920 & 16 June 1921 & 12 & -17.55 & -1.46 & -1.94 \\
& 16 January 1952 & 16 December 1952 & 12 & -12.67 & -1.06 & -1.47 \\
\multirow{2}{*}{ Zone 3 } & 16 December 1945 & 16 September 1946 & 10 & -10.37 & -1.04 & -1.73 \\
& 16 January 1918 & 16 October 1918 & 10 & -10.71 & -1.07 & -1.62 \\
& 16 April 1968 & 16 May 1969 & 14 & -15.07 & -1.08 & -1.42 \\
Zone 4 & 16 December 1970 & 16 November 1971 & 12 & -15.47 & -1.29 & -1.65 \\
& 16 August 1987 & 16 June 1988 & 11 & -11.27 & -1.02 & -1.36 \\
& 16 December 1999 & 16 September 2000 & 10 & -9.75 & -0.97 & -1.53 \\
& 15 February 2004 & 16 November 2004 & 10 & -12.27 & -1.23 & -1.94 \\
\hline \multirow{2}{*}{ Zone 5 } & 16 April 1968 & 16 January 1970 & 22 & -23.12 & -1.05 & -1.39 \\
& 16 September 2001 & 16 November 2002 & 15 & -15.80 & -1.05 & -1.44 \\
& 15 February 2000 & 16 March 2001 & 14 & -14.38 & -1.03 & -1.38 \\
& 16 July 1920 & 16 June 1921 & 12 & -13.62 & -1.13 & -1.39 \\
\hline
\end{tabular}

Zone 5, covering almost all of Sindh, experienced its first long-term drought at the start of the 1920s, which lasted a total of 12 months. The second drought, occurring in the late 1960s, lasted nearly two years with an intensity of -1.05 . The longest, and the most severe, drought to have struck Pakistan as a whole was from 1999-2002.

\section{Discussion}

The zones produced after running the SKATER algorithm to a large extent reflect the climatological regions that exist in Pakistan. The trend analysis indicated no statistically significant trend-at a confidence interval of 95\% - for SPEI in zone 1, whereas, in zones 2 and 3, the trend was positive. Zones 4 and 5 showed a statistically significant decreasing trend. Similar results were obtained by Adnan [17] where he found that rainfall in Punjab and Khyber Pakhtunkhwa (KPK) had increased by $2.45 \mathrm{~mm}_{\text {year }}{ }^{-1}$ and $1.55 \mathrm{~mm}_{\text {year }}{ }^{-1}$, corresponding to the wetting trend we found in zones 2 and 3. A statistically significant decrease in annual evapotranspiration was also reported by Adnan [17] in KPK and Punjab at the rate of $-0.36 \mathrm{~mm} \mathrm{year}^{-1}$ and $-0.43 \mathrm{~mm}_{\text {year }}{ }^{-1}$, further validating our results obtained over zones 2 and 3. This decrease in annual evapotranspiration could be due to the expansion and intensification of irrigation in this area, which would increase air humidity and lower the PET. Additionally, the mean annual trends in minimum and maximum temperatures over different provinces also confirm our findings. Over Sindh and Baluchistan, an increasing trend was reported for both maximum and minimum temperatures, whereas a decreasing trend was reported for KPK. The trend for maximum temperature showed a decrease in Punjab, but an increase was noted for minimum temperature.

Furthermore, it can be concluded based on the historic trends that zone 1 is likely to face longer duration and severer droughts as opposed to zone 2, which will face short duration-and less severe-droughts. No trend in any drought characteristic was found to be statistically significant for zone 3 . Zone 4 is likely to experience increasingly severe and intense droughts in the future. Droughts 
having significantly worse peaks are expected to occur in zone 5 . Drought mitigation plans, therefore, must be prepared keeping in mind the trends observed for the characteristics of droughts in each zone.

Moreover, the results also revealed prolonged periods of drier than normal conditions which occurred in each zone. Two of these periods, the 1920s and 1999-2000, are particularly interesting as they occurred in three zones for at least ten months. It is noteworthy that, although the drought of 1999 has received significant attention, the drought that occurred in 1920 has not been reported as extensively.

Additionally, the influence of climate change on the drought characteristics is also evident, especially in zones 4 (Southern Balochistan) and 5 (Sindh Province) which have an arid climate and display a decreasing trend in SPEI. Drought characteristics averaged for every 15 years revealed worrisome outcomes for zones 4 and 5. The drought count was at a maximum for the period 2000-2015 in zones 4 (27) and 5 (24). Similarly, the mean drought duration was maximum in zone 4 at 3.815 months. For Zone 5, the highest mean duration occurred in 1970-1984 with a value of 3.33 months, which is closely followed in the post-2000 period with a value of 3.208 months. Mean drought severity, similarly, was the lowest-with a value of -4-after 2000 in zone 4 . Therefore, zones 4 and 5 may display the worsening effects of climate change, which could be further studied by looking at the atmospheric circulation modes that transport water to or from these specific regions and how they have changed and are projected to change.

\section{Conclusions}

Droughts are natural hazards that may aggravate in the coming years, especially because of the effects of climate change. Pakistan is highly vulnerable to the adverse impacts that result from droughts. Therefore, it is crucial to understand the behavior of droughts in Pakistan to plan accordingly. This research, therefore, improves the understanding of meteorological drought behavior in Pakistan.

The Standardized Precipitation Evapotranspiration Index (SPEI) was chosen as an indicator of drought. Gridded precipitation and evapotranspiration data from Climate Research Unit (CRU), at a resolution of $0.5^{\circ}$ by $0.5^{\circ}$, was downloaded for the time period 1902-2015. SPEI was then calculated for each grid cell, followed by applying a clustering algorithm to group Pakistan into five homogeneous and contiguous zones based on SPEI. The run theory was employed to identify drought events where the threshold value of SPEI was taken to be -0.5. Spatial "K" luster Analysis using a Tree Edge Removal (SKATER) method was used to produce the meteorological drought homogeneous zones. The Modified Mann-Kendall trend test was applied to the SPEI and drought characteristics in each zone.

Overall, the study sheds light on the variability of drought characteristics in different zones of Pakistan. Nevertheless, there were some limitations to this study. We only considered 3-month SPEI, which is suitable for short-term meteorological drought modeling. Other time scales need to be explored to provide a holistic view of the drought variability in Pakistan. In addition, the SPEI drought index used here was based on one specific dataset (CRU) of precipitation and other climate fields. A recent evaluation of numerous precipitation products in the Indus Basin, which includes most of Pakistan, found that the CRU precipitation field appears to have realistic mean amount and long-term trends relative to station observations, suggesting that temporal homogeneity and bias are on the whole successfully controlled by CRU's interpolation and quality control procedures [27]. However, a sensitivity analysis, possibly including intercomparison to SPEI derived from other historic climate datasets, would help confirm the drought patterns and trends seen here. Furthermore, drought indices developed specifically for agricultural and hydrological droughts, such as PDSI and Streamflow Drought Index (SDI), must be incorporated in future research to understand the transition among the different types of drought. This would greatly help in the understanding of different types of droughts and their interlinkages.

Author Contributions: Conceptualization, S.J., G.H.D., K.A., and N.Y.K.; Methodology, S.J., G.H.D., K.A., and N.Y.K.; Software and Visualization, S.J.; Writing—original draft, S.J.; Writing—review and editing, S.J., G.H.D., K.A., and N.Y.K. 
Funding: N.Y.K. was supported by the United States Agency for International Development through the U.S.-Pakistan Center for Advanced Studies in Water (USPCAS-W) and by the National Oceanic and Atmospheric Administration Educational Partnership Program with Minority-Serving Institutions-Cooperative Science Center for Earth System Sciences and Remote Sensing Technologies under the Cooperative Agreement Grant No. NA16SEC4810008. In addition, authors would like to acknowledge the financial support for this study from the USPCAS-W, Mehran University of Engineering and Technology, Jamshoro, Pakistan established with the grant of United States Agency for International Development (USAID). The contents are the sole responsibility of the authors and do not necessarily reflect the views of USPCAS-W, USAID or the United States or Government of Pakistan.

Conflicts of Interest: The authors declare no conflict of interest.

\section{References}

1. Panagoulia, D.G.; Dimou, G. Definitions and effects of droughts. Div. Water Resour. 1998, 7, $2-5$.

2. Anjum, S.; Saleem, M.; Cheema, M.; Bilal, M.; Khaliq, T. An assessment to vulnerability, extent, characteristics and severity of drought hazard in Pakistan. Pak. J. Sci. 2012, 64, 138-143.

3. Pakistan Weather Portal History of Drought in Pakistan-In Detail. Available online: https:// pakistanweatherportal.com/2011/05/08/history-of-drought-in-pakistan-in-detail/ (accessed on 19 September 2019).

4. Durrani, Z.K. Lessons for Pakistan from Droughts in the Past. Available online: https://cscr.pk/explore/ themes/energy-environment/lessons-pakistan-droughts-past/ (accessed on 20 July 2018).

5. Sheikh, M.M. Drought management and prevention in Pakistan. Sci. Vis. 2001, 7, 117-131.

6. Edossa, D.C.; Woyessa, Y.E.; Welderufael, W.A. Spatiotemporal analysis of droughts using self-calibrating Palmer's Drought Severity Index in the central region of South Africa. Theor. Appl. Climatol. 2016, 126, 643-657. [CrossRef]

7. Palmer, W.C. Meteorologic Drought; U.S. Dep. Commer. Weather. Res. Paper No. 45; Weather Bureau: Washington, DC, USA, 1965; p. 58.

8. Gocic, M.; Trajkovic, S. Spatiotemporal characteristics of drought in Serbia. J. Hydrol. 2014, 510, 110-123. [CrossRef]

9. Thomas, M.B.; Nolan, D.J.; John, K. The Relationship of Drought Frequency and Duration to Time Scales. In Proceedings of the 8th Conference on Applied Climatology; American Meteorological Society: Boston, MA, USA, 1993; Volume 17.

10. Dabanlı, İ.; Mishra, A.K.; Şen, Z. Long-term spatio-temporal drought variability in Turkey. J. Hydrol. 2017, 552, 779-792. [CrossRef]

11. Ashraf, M.; Routray, J.K. Spatio-temporal characteristics of precipitation and drought in Balochistan Province, Pakistan. Nat. Hazards 2015, 77, 229-254. [CrossRef]

12. Haroon, M.A.; Zhang, J.; Yao, F. Drought monitoring and performance evaluation of MODIS-based drought severity index (DSI) over Pakistan. Nat. Hazards 2016, 84, 1349-1366. [CrossRef]

13. Xie, H.; Ringler, C.; Zhu, T.; Waqas, A. Droughts in Pakistan: A spatiotemporal variability analysis using the Standardized Precipitation Index. Water Food Secur. Chall. Pak. 2016, 38, 116-127. [CrossRef]

14. Guttman, N.B. Comparing the Palmer Drought Index and the Standardized Precipitation Index. J. Am. Water Resour. Assoc. 1998, 34, 113-121. [CrossRef]

15. Zhang, X.; Zwiers, F.W.; Hegerl, G.C.; Lambert, F.H.; Gillett, N.P.; Solomon, S.; Stott, P.A.; Nozawa, T. Detection of human influence on twentieth-century precipitation trends. Nature 2007, 448, 461-465. [CrossRef] [PubMed]

16. Vicente-Serrano, S.M.; Beguería, S.; López-Moreno, J.I. A multiscalar drought index sensitive to global warming: The standardized precipitation evapotranspiration index. J. Clim. 2010, 23, 1696-1718. [CrossRef]

17. Adnan, S. Spatio-Temporal Distribution of Drought and its Characteristics over Pakistan. Ph.D. Dissertation, Commission on Science and Technology for Sustainable Development in the South University, Islamabad, Pakistan, 2016.

18. Guo, H.; Bao, A.; Liu, T.; Jiapaer, G.; Ndayisaba, F.; Jiang, L.; Kurban, A.; De Maeyer, P. Spatial and temporal characteristics of droughts in Central Asia during 1966-2015. Sci. Total. Environ. 2018, 624, 1523-1538. [CrossRef] [PubMed]

19. Krakauer, N.Y.; Lakhankar, T. Trends in Drought over the Northeast United States. Water 2019, $11,1834$. [CrossRef] 
20. Potop, V.; Boronean, C. Observed evolution of drought episodes assessed with the Standardized Precipitation Evapotranspiration Index (SPEI) over the Czech Republic. EGU General Assembly 2012, 14, 10010.

21. Liu, X.; Wang, S.; Zhou, Y.; Wang, F.; Li, W.; Liu, W. Regionalization and Spatiotemporal Variation of Drought in China Based on Standardized Precipitation Evapotranspiration Index (1961-2013). Adv. Meteorol. 2015, 2015, 950262. [CrossRef]

22. Tan, C.; Yang, J.; Li, M. Temporal-spatial variation of drought indicated by SPI and SPEI in Ningxia Hui Autonomous Region, China. Atmosphere 2015, 6, 1399-1421. [CrossRef]

23. Tian, L.; Quiring, S.M. Spatial and temporal patterns of drought in Oklahoma (1901-2014). Int. J. Climatol. 2019, 39, 3365-3378. [CrossRef]

24. Zaman, Q.U.; Rasul, G. Agro-Climatic Classification of Pakistan. Q. Sci. Vis. 2004, 9, 59-66.

25. Qamar Uz Zaman, C. Climate Change Profile of Pakistan; Asian Development Bank: Mandaluyong, PH, USA, 2017.

26. Mahessar, A.A.; Qureshi, A.L.; Dars, G.H.; Solangi, M.A. Climate change impacts on vulnerable Guddu and Sukkur Barrages in Indus River, Sindh. Sindh Univ. Res. J. 2017, 49, 137-142.

27. Krakauer, N.Y.; Lakhankar, T.; Dars, G.H. Precipitation Trends over the Indus Basin. Climate 2019, 7, 116. [CrossRef]

28. Rehman, S.; Shah, M.A. Rainfall Trends in Different Climate Zones of Pakistan. Pak. J. Meteorol. 2012, 9, $37-47$.

29. Frenken, K. Irrigation in Southern and Eastern Asia in figures: AQUASTAT Survey-2011. In Water Reports; Food and Agriculture Organization of the United Nations (FAO): Rome, Italy, 2012; No. 37.

30. Beguería, S.; Latorre, B.; Reig, F.; Vicente-Serrano, S.M. sbegueria/SPEIbase: Version 2.5.1. Glob. SPEI Database 2017.

31. Schneider, U.; Becker, A.; Finger, P.; Meyer-Christoffer, A.; Ziese, M.; Rudolf, B. GPCC's new land surface precipitation climatology based on quality-controlled in situ data and its role in quantifying the global water cycle. Theor. Appl. Climatol. 2014, 115, 15-40. [CrossRef]

32. Harris, I.; Jones, P.D.; Osborn, T.J.; Lister, D.H. Updated high-resolution grids of monthly climatic observations-The CRU TS3.10 Dataset. Int. J. Climatol. 2014, 34, 623-642. [CrossRef]

33. Briffa, K.R.; Jones, P.D. Global surface air temperature variations during the twentieth century: Part 2, implications for large-scale high-frequency palaeoclimatic studies. Holocene 1993, 3, 77-88. [CrossRef]

34. Thornthwaite, C.W. An Approach toward a Rational Classification of Climate C. Geogr. Rev. 1948, 38, 55-94. [CrossRef]

35. Yuan, S.; Quiring, S.M. Drought in the U.S. Great Plains (1980-2012): A sensitivity study using different methods for estimating potential evapotranspiration in the Palmer Drought Severity Index. J. Geophys. Res. Atmos. 2014, 119, 3825-3856. [CrossRef]

36. Mamassis, N.; Panagoulia, D.; Novkovic, A. Sensitivity analysis of penman evaporation method. Glob. Nest J. 2014, 16, 628-639.

37. Westerhoff, R.S. Using uncertainty of Penman and Penman-Monteith methods in combined satellite and ground-based evapotranspiration estimates. Remote Sens. Environ. 2015, 169, 102-112. [CrossRef]

38. Assunção, R.M.; Neves, M.C.; Câmara, G.; Da Costa Freitas, C. Efficient regionalization techniques for socio-economic geographical units using minimum spanning trees. Int. J. Geogr. Inf. Sci. 2006, 20, 797-811. [CrossRef]

39. Jungnickel, D. Graphs, Networks and Algorithms; Springer: Berlin, Germany, 1999.

40. Yevjevich, V. An objective approach to definitions and investigations of continental hydrologic droughts. J. Hydrol. 1969, 7, 353.

41. Mohammed, S.; Alsafadi, K.; Mohammad, S.; Mousavi, N. Drought Trends in Syria from 1900 to 2015. In Proceedings of the 4th International Congress of Developing Agriculture, Natural Resources, Environment and Tourism of Iran, Tabriz Islamic Art University In cooperation with Shiraz University and Yasouj University, Tabriz, Iran, 14 August 2019.

42. Hamed, K.H.; Rao, A.R. A modified Mann-Kendall trend test for autocorrelated data. J. Clin. Oncol. 2018, 36, 522. [CrossRef]

43. Kendall, M.G. Rank Correlation Methods; Griffin: Oxford, UK, 1948. 
44. Sen, P.K. Estimates of the Regression Coefficient Based on Kendall's Tau. J. Am. Stat. Assoc. 1968, 63, 1379-1389. [CrossRef]

45. Ullah, H.; Akbar, M.; Khan, F. Construction of homogeneous climatic regions by combining cluster analysis and L-moment approach on the basis of Reconnaissance Drought Index for Pakistan. Int. J. Climatol. 2019, 1-18. [CrossRef] article distributed under the terms and conditions of the Creative Commons Attribution (CC BY) license (http://creativecommons.org/licenses/by/4.0/). 